\title{
АКУСТОЕЛЕКТРОННІ СЕНСОРИ
}

\section{ACOUSTOELECTRONIC SENSORS}

УДК 539.2:539.4

PACS 43.40.LE, 85.30.-Z, 73.40.VZ

\section{ДИНАМІКА АКУСТИЧНОЇ ЕМІСІЇ У ЛОКАЛЬНО-НЕОДНОРІДНО ТЕРМОНАПРУЖЕНИХ ГЕТЕРОСТРУКТУРАХ}

\author{
О. В. Ляшенко \\ Київський національний університет імені Тараса Шевченка, \\ 03680, м.Київ, пр. Глушкова, 2/1, \\ e-mail: lyashenk@univ.kiev.ua
}

\section{ДИНАМІКА АКУСТИЧНОЇ ЕМІСІЇ У ЛОКАЛЬНО-НЕОДНОРІДНО ТЕРМОНАПРУЖЕНИХ ГЕТЕРОСТРУКТУРАХ}

\section{О. В. Ляшенко}

Анотація. В роботі проведено аналіз динаміки акустичної емісії, що супроводжує деградацію і локальні процеси релаксації та дефектоутворення в локально-неоднорідно термонапружених гетероструктурах In $G a N / G a N$ та $G a A s P / G a P$ при покроковому збільшенні прямого постійного струму. Показано, що динаміка АЕ добре узгоджується з основними висловленими припущеннями - AE є детермінованим в часі хаотичним релаксаційним процесом, параметри АЕ залежать від величини зміни та швидкості зміни рівня зовнішнього фіксованого навантаження, кількості однотипних джерел АЕ, активованих цим впливом на протязі часу його дії, а також дисперсією деяких параметрів цих джерел АЕ.

Ключові слова: динаміка акустичної емісії, гетероструктура, дефект

\section{THE DYNAMICS OF ACOUSTIC EMISSION IN LOCALLY-IS NON-UNIFORMLY THERMO STRAINED HETEROSTRUCTURES}

\section{O. V. Lyashenko}

Abstract. In operation the analysis of dynamics of an acoustic emission that accompanies with degradation and local processes of a relaxation and a defect formation in locally-is non-uniformly thermostrained heterostructures $\operatorname{In} G a N / G a N$ and $G a A s P / G a P$ at step-by-step magnification of a direct current is lead. It is shown, that dynamics $\mathrm{AE}$ is well coordinated with the basic guesses - $\mathrm{AE}$ is the chaotic relaxation process determined in time, parameters AE depend on quantity of change and velocity of change of a level of the exterior fixed loading, quantity of the same sources AE activated by this influence during time of its activity, and also a variance of some parameters of these sources $\mathrm{AE}$

Keywords: The dynamics of acoustic emission, heterostructure, defect 


\section{ДИНАМИКА АКУСТИЧЕСКОЙ ЭМИССИИ В ЛОКАЛЬНО-НЕОДНОРОДНО ТЕРМОНАПРЯЖЕННЫХ ГЕТЕРОСТРУКТУРАХ}

\section{О. В. Ляшенко}

Аннотация. В работе проведен анализ динамики акустической эмиссии, что сопровождает деградацию и локальные процессы релаксации и дефектообразования в локально-неоднородно термонапряженных гетероструктурах InGaN/GaN и GaAsP/GaP при пошаговом увеличении прямого постоянного тока. Показано, что динамика AЕ хорошо согласовывается с основными предположениями - АЕ является детерминированным во времени хаотическим релаксационным процессом, параметры АЕ зависят от величины изменения и скорости изменения уровня внешней фиксированной нагрузки, количества однотипных источников АЕ, активированных этим влиянием в течение времени его действия, а также дисперсией некоторых параметров этих источников АЕ

Ключовые слова: динамика акустической эмиссии, гетероструктура, дефект

Детермінований зовнішній вплив призводить до такої ж детермінованої реакції лінійної системи [1]. Більшість фізичних процесів у твердих тілах є детермінованими - тобто в рамках тієї або іншої системи рівнянь вони можуть бути описані (передбачені) виходячи із заздалегідь заданих початкових умов [1]. Однак нелінійним системам (зокрема, пружно-нелінійним - гетероструктурам) притаманна висока чутливість до початкових умов (для гетероструктур - початковий стан та передісторія дефектної системи), яка можуть призводити до їх хаотичної поведінки в часі [1,2] їх параметрів та характеристик. Відповідно, нерегулярний або хаотичний рух породжений у нелінійних системах є проявом певних динамічних закономірностей, які на перший погляд “однозначно” повинні були б визначати еволюцію в часі стану системи при відомій наперед іiі передісторіï.

Одним 3 відомих нелінійних та хаотичних явищ є акустична емісія (AE) матеріалів $[2,3,4,5]$, зокрема у світловипромінюючих гетероструктурах $[6,7,8,9]$. Традиційні підходи $[3,4,5]$ до явища акустичної емісії визнача-

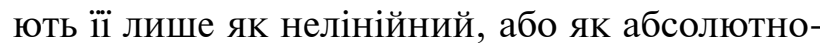
хаотичний процес, шо зумовлено складністю точного формулювання задачі $\mathrm{AE}[3,10,11]-$ задачі про спонтанне хаотичне випромінювання акустичних хвиль шумового характеру рухомими структурними дефектами при релаксації надлишкових механічних та термомеханічних напруг, викликаної зовнішнім впливом $[2,12]$. Умовою, шо звичайно дозволяє проводити аналіз процесу AE, $є$ припушення про незалежність джерел АЕ, яке справедливе тільки на по- чаткових стадіях навантаження та виникнення AЕ, далеких від руйнування зразка.

Ця стадія ще відповідає виконанню закону Кайзера - АЕ виникає в досліджуваному зразку лише при перевищенні в наступному циклі навантаження зовнішнього впливу, при якому AE загасла у попередньому циклі $[2,3,4,5,12]$. В гетероструктурах через наявність (навіть - у початковому стані) одночасно кількох типів дефектів $[6,7,8,13,14,15,16,17]$, кожен 3 яких може бути (самостійно, або в складі комплексів) джерелом АЕ $[6,7,8]$, прогнозоване виконання закону Кайзера неочевидно.

Варто відмітити, що існування двох типових видів АЕ - низькоенергетичної неперервної АЕ та високоенергетичної дискретної $\mathrm{AE}$ $[2,3,4,5]$ немає загальноприйнятого пояснення. Однак, здебільшого неперервну АЕ пов'язують 3 несинхронним рухом (утворенням) низьковимірних дефектів, зокрема - дислокацій $[3,4,5,11,12]$, а дискретну AE - зі зміною стану (утворенням) тривимірних дефектів - тріщин $[2,3,4,5]$, синхронним рухом (утворенням) комплексів дислокацій $[2,12]$ та внутрішніх залишкових механічних напруг $[6,7,8]$.

Додатковими особливостями, що суттєво впливають на динаміку АЕ гетероструктур можна вважати утворення локально-неоднорідних термомеханічних напруг при протіканні струму, просторовий розподіл яких по-перше корелює 3 шаруватою структурою (внаслідок епітаксійних технологій та існування активного шару), а по-друге, через існування низки явищ, зокрема - "current crowding" [18,19], що створюють неоднорідний розподіл густини струму $J_{i}$ через площу гетропереходу — градієнтів термонапруг, 
перпендикулярних до напрямку трубки струму. Фактично, при протіканні струму ці два “просторово-ортогональні” розподіли механічних напруг формують “замкнені” локальні області неоднорідних механічних напруг вздовж трубки струму, які є потенційними (і надзвичайно потужними) джерелами дискретної високоенергетичної АЕ.

$\mathrm{У}$ роботі проведено аналіз динаміки акустичної емісії, що супроводжує деградацію і локальні процеси релаксації та дефектоутворення в локально-неоднорідно термонапружених гетероструктурах InGaN/GaN та GaAsP/GaP при покроковому збільшенні прямого постійного струму.

Розглянемо деякі обмеження, які накладаються на довільну нелінійну систему з різновимірними дефектами структури, на яку здійснюється довільний зовнішній вплив та для якої виконується закон Кайзера.

Надпороговому значенню узагальненої зовнішньої сили $\Phi_{i}$ відповідає певна енергія активації джерела $E_{a i}$, тоді довільному $i$-му кроку зміни $\Delta \Phi_{i}$ буде відповідати певний інтервал значень енергій активації джерел $\mathrm{AE}\left[E_{a i}, E_{a i}+\Delta E_{a i}\right]$ та, відповідно, певна кількість активних (для цього або більшого рівня впливу) джерел $\mathrm{AE} \alpha_{i}$, які послідовно можуть “спрацювати” (змінити стан) за непевний проміжок часу. Загальна кількість потенційно активних джерел АЕ в цьому випадку

$$
Z_{0}=\sum_{i=k}^{N} \alpha_{i},
$$

де $k-$ значення $i$, при якому відбувається порогове збудження АЕ, тобто $E_{a k}$ та $\Phi_{k}-$ це мінімальна енергія активації та поріг збудження АЕ відповідно.

Число $n$ обмежує величину зовнішньої узагальненої сили $\Phi_{n}$ та максимальну енергію активації джерела АЕ $E_{a n}$ енергією, достатньою для розриву будь-яких міжатомних зв'язків в досліджуваному матеріалі. Перевищення значень $\Phi_{n}$ та $E_{a n}$ неможливе і тому навіть у зруйнованій гетероструктурі завжди залишаються пасивні джерела АЕ.

Для невзаємодіючих джерел АЕ гетероструктур крокове навантаження із постійним збільшенням струму $I_{i}$ (фактично $\Phi_{i}$ ) повинно призводити к послідовному спрацюванню (за деякій час) певної кількості джерел АЕ $ү \alpha_{i}$ $(\eta<1)$ з групи джерел АЕ (кількістю $\left.-\alpha_{i}\right)$, що відповідають кроку навантаження $\Delta I_{i}=I_{i}-I_{i-1}$. Оскільки тривалість процесу спрацювання джерел АЕ при сталому навантаженні характеризується певним часом $\tau_{i}$ та часом затримки початку АЕ $\tau_{з i}$ після збільшення $I_{i}$, мінімальний час експерименту $t_{\min }$ з кроковим навантаженням, при якому ще може виконуватися закон Кайзера

$$
t_{\min }=\sum_{i=0}^{N}\left(\tau_{i}+\tau_{3 i}\right),
$$

де $\tau_{i}-$ час спрацювання та $\tau_{3 i}-$ час затримки спрацювання всіх джерел АЕ, що мають значення енергії активації в інтервалі $\left[E_{a i}, E_{a i}+\Delta E_{a i}\right]$, причому очевидно, що

$$
\tau_{i}+\tau_{3 i} \leq \sum_{n=1}^{\alpha_{i}}\left(\tau_{n i}+\tau_{3 . n i}\right),
$$

де $\tau_{n i}$ та $\tau_{\text {з.ni }}$ - час спрацювання та час затримки перед спрацюванням $n$-го джерела $i$-ї групи джерел АЕ з енергією активації в інтервалі $\left[E_{a i}\right.$, $\left.E_{a i}+\Delta E_{a i}\right]$ та кількістю джерел $\alpha_{i}$. Таким чином, враховуючи (2), отримаємо:

$$
t_{\min } \leq \sum_{i=0}^{N} \sum_{n=1}^{\alpha_{i}}\left(\tau_{n i}+\tau_{3 . n i}\right)
$$

Слід зауважити, що у співвідношеннях (3) та (4) ввійшли нульові часи $\tau_{i}$ (де $i<k$ ) які відповідають допороговим значенням $I_{i}<I_{k}$ та $E_{a i}<E_{a k}$, тобто допороговим для АЕ значенням вПливу.

Оскільки процес покрокового навантаження - спрацювання джерел АЕ суттєво нерівномірний в часі, зокрема для гетероструктур при протіканні струму - рис.1, 2 та 3, кожному $\tau_{i}$ відповідають суттєво різна кількість $\alpha_{i}$, які відрізняються як $\tau_{з і}$, так і динамікою спрацювання різних джерел АЕ різної фізичної природи, але які мають однакову енергією активації $E_{a i}$, точніше, відповідне до нього однакове значення $I_{i}$, оскільки функціональний зв'язок $E_{a i}$ $\left(I_{i}\right)$ може бути суттєво різний як для джерел $\mathrm{AE}$ різної фізичної природи, так і для різних локальних областей матеріалу (гетероструктури).

Відмітимо, що формальна умова (4) визначає мінімальний час експерименту з покроковим збільшенням навантаження (зовнішнього впливу) для конкретного досліджуваного зразка і фактично ніколи не може бути виконана, оскільки звичайно експериментальне визначення $\tau_{i}$ досить неточне і майже єдиним емпіричним критерієм завершення АЕ на $i$-тому кроці на- 
вантаження (вибору $\tau_{i}$ ) є зменшення інтенсивності АЕ $\dot{N}$ до рівня шумів електронної апаратури на протязі деякого $\Delta \tau_{i}=10^{1} \ldots 10^{3}$ сек, що в багатьох випадках значно збільшує час експерименту, оскільки всі часи $\tau_{i}$ (де $i<k$ ) які повинні бути нульові, суттево збільшуються, а $\Delta \tau_{i}$ в загальному випадку для вказаних значень може задовольняти умові як $\Delta \tau_{i}<<\tau_{i}$, так і $\Delta \tau_{i}>>\tau_{i}$.

Тому реальний час експерименту $t$, при якому можна очікувати виконання закону Кайзера, відповідає співвідношенню

$$
\sum_{i=0}^{N} \sum_{n=1}^{\alpha_{i}}\left(\tau_{n i}+\tau_{3 . n i}\right) \leq t \leq \sum_{i=0}^{N}\left(\sum_{n=1}^{\alpha_{i}}\left(\tau_{n i}+\tau_{3 . n i}\right)+\Delta \tau_{i}\right) .
$$

Зменшення цього часу призводить до порушення закону Кайзера та виникненню відомого ефекту Фелісіті - прояв АЕ при циклічних навантаженнях із зростаючим у кожному наступному $i$-тому циклі навантаженням не при $\Phi_{i}$, а при значеннях $\Phi_{i-m}$, де $m$ може значно перевищувати 1. Фактично ефект Кайзера можна розглядати як частковий випадок ефекту Фелісіті, коефіцієнт якого $F=\Phi_{i+} / \Phi_{i} \geq 1$.

Оскільки кожна гетероструктура має індивідуальний (наперед невідомий) набір джерел AE, а вибір параметрів покрокового навантаження - збільшення струму може бути здійснений на сьогодні тільки емпірично, в наших дослідах було виявлено кілька варіантів розвитку процесів.

На рис. 1 представлені гістограмами часового розподілу інтенсивності АЕ $\dot{N}$ для послідовних інтервалів часу 10 сек при покроковому збільшенні струму через гетероструктуру для найбільш типового варіанту динаміки АЕ у гетероструктурах. 3 рис.1 випливає, що при покроковому стрибкоподібному збільшенні густини струму $J$ до $J_{d s t}-$ густини струму руйнування, зменшується час затримки виникнення $\mathrm{AE} t_{d}-$ тобто час індивідуального “розвитку" джерел АЕ. Одночасно відбувається зміна інтенсивності АЕ $\dot{N}$ в послідовних часових проміжках. Якщо для малих надпорогових $J>J_{t h}$ відбувається монотонне збільшення $\dot{N}$ з часом та наступне загасання, то при $J \sim J_{d s t}$ інтенсивність АЕ має максимум вже в перші 10 сек. Тривалість АЕ також змінюється в наступних кроках збільшення струму, а саме - при $J>J_{\text {th }}$ монотонно зростає, досягаючи максимуму при $J \sim J_{d s t}$ (одночасно $\dot{N}$ швидко зростає). В заключній фазі експерименту - при значенні $J=J_{d s t}$ тривалість АЕ різко скорочується, а $\dot{N}$ має максимум в перші 10 (або і в 1-шу) секунди.
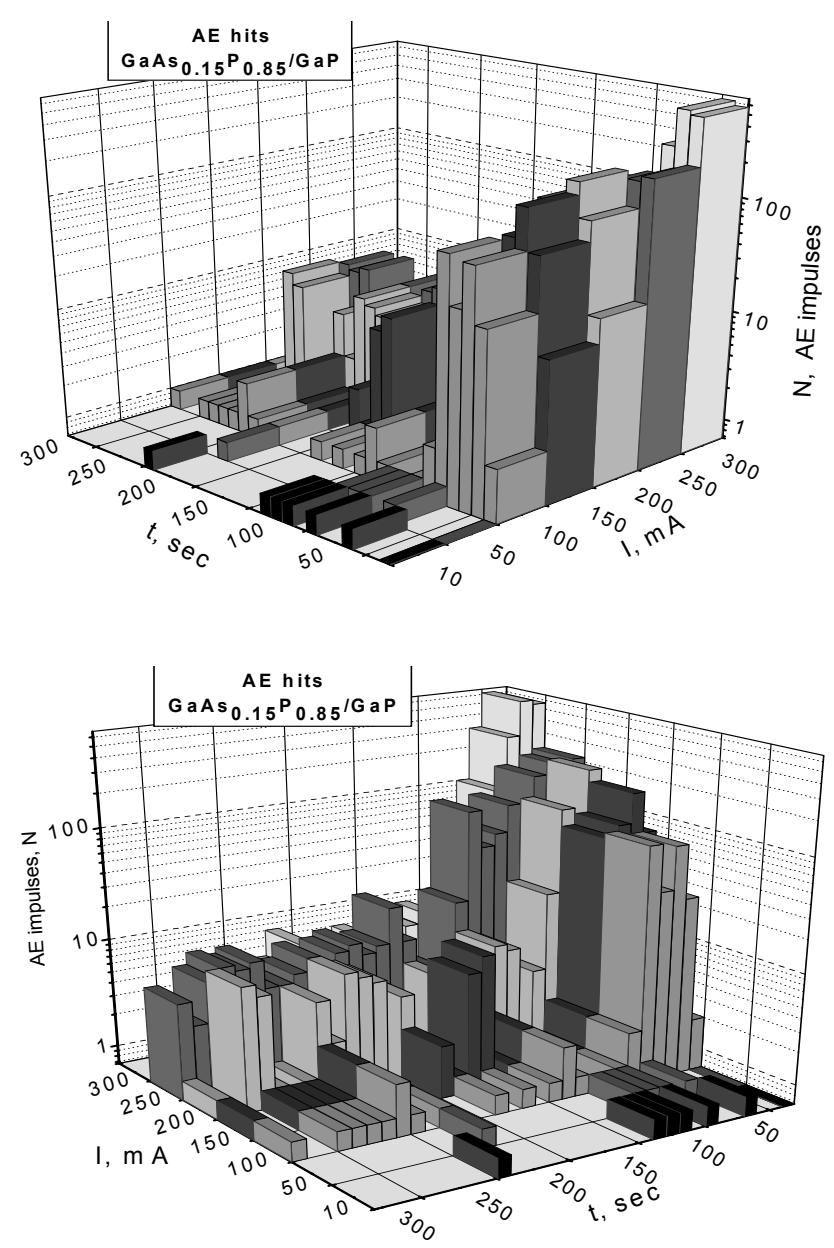

Рис. 1. Залежності $\dot{N}(t)$ для типового варіанту динаміки $\mathrm{AE}$ гетероструктур $G a A s_{0,15} P_{0.85} / G a P:$ a - початок та б - закінчення процесу АЕ (діаграми розвернуті під кутом $90^{\circ}$ )

Цей варіант динаміки АЕ в цілому задовольняє висловленим припущенням стосовно параметрів покрокової зміни зовнішнього впливу та активації джерел АЕ - в даному випадку прямого струму гетероструктури. Варто зауважити, що порогове для виникнення АЕ значення прямого струму означає початок деградаційних (або ж прискорення релаксаційних) процесів в структурі, зокрема - оборотних та необоротних зсувів спектрів електролюмінісценції та деградацій квантового виходу, зростання $\dot{N}-$ прискорення процесів, а наступне зменшення $\dot{N}$ чи припинення АЕ вказує на необоротні перебудови, що відбулись в локальних 
областях. Стабільне зростання інтенсивності АЕ при підвищенні $J$ вказує на досягнення передруйнівного стану.

Цим, зокрема, додатково пояснюється виявлена у [20,21,22] кореляція сигналів $\mathrm{AE} 3$ флуктуаціями квантового виходу і струму - iз збільшенням струму АЕ спостерігається в малому інтервалі часу з високою інтенсивністю, що підвищує вірогідність виявлення цієї кореляції.

На рис. 2 та рис. 3 представлені інші типові варіанти динаміки АЕ для яких крок підвищення струму та час між підвищеннями струму були такими ж, як для гетероструктур на рис.1, але через індивідуальні особливості дефектної системи цих гетероструктур були вибрані "невірно”. Фактично, для гетероструктур на рис. 2 та рис.3 була порушена умова незалежності джерел АЕ, що забезпечує виконання закону Кайзера, через занадто високу кількість одночасно активованих джерел АЕ, які створюючи далекодіючі поля пружних напруг в момент спрацювання, виконували роль каталізатора для "синхроного" спрацювання джерел АЕ заданого $\left[E_{a i}, E_{a i}+\Delta E_{a i}\right]$ та “передчасного" спрацювання джерел $\mathrm{AЕ}$ з кількох діапазонів $\left[E_{a i+m}\right.$, $\left.E_{a i+m}+\Delta E_{a i+m}\right]$, де $m=1,2,3 \ldots$ Тобто наслідком такої взаємодії може бути поява нових джерел $\mathrm{AE}, ~ з$ відносно малою енергією активації, які відразу ж спрацьовують при заданому значенні $J_{i}$ (надпороговому для них), або активізація групи пасивних джерел АЕ з енергією активації, занадто великою (без взаємодії сусідніх активних джерел $\mathrm{AE)} \mathrm{для} \mathrm{заданої} J_{i}$.

Так, рис.2 відповідає "занадто швидкому" підвищенню струму та "занадто великому" кроку цього підвищення, тобто при занадто великому діапазоні $\left[E_{a i}, E_{a i}+\Delta E_{a i}\right]$ та кількості одночасно активованих джерел AE $\alpha_{i}$. При цьому виконувалось

$$
t_{\min }<\sum_{i=0}^{N}\left(\tau_{i}+\tau_{3 i}\right),
$$

що призвело до досягнення максимуму $\dot{N}$ вже в першому часовому проміжку (для струмів $J \geq 10 J_{\text {nот }}$ ) та швидкого руйнування.

На рис.3 представлений варіант “занадто великого” кроку підвищення струму (занадто великий діапазон $\left[E_{a i}, E_{a i}+\Delta E_{a i}\right]$ та кількість одночасно активованих джерел АЕ $\alpha_{i}$.) але з "правильно вибраним" часом між підвищеннями $t_{\text {min }}$. В результаті при $J=J_{d s t}$ відбувався “повільний" процес руйнування, що супроводжувався $\mathrm{AE}$.
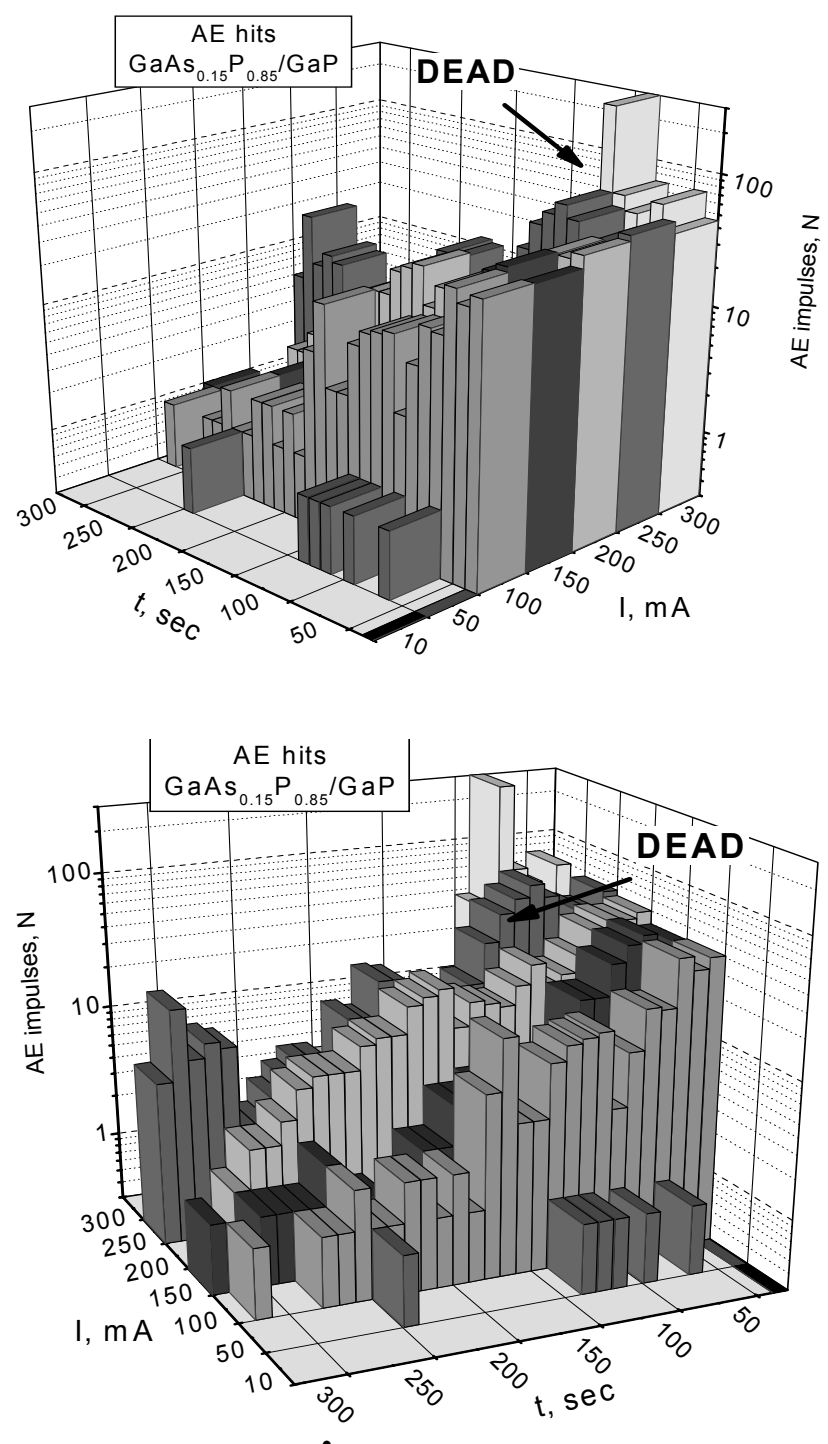

Рис. 2. Залежності $\dot{N}(t)$ для динаміки АЕ з “занадто швидким" підвищенням струму та “занадто великим” кроком: а - початок та б - закінчення процесу АЕ (діаграми розвернуті під кутом 90)

Таким чином, оскільки навіть однотипні джерела АЕ розрізняються своїми параметрами, зокрема $E_{a i}$, тому для активації всіх (або значної частини) джерел потрібен певний час, який може бути значно більше за час певної фази експерименту. При початкових (після порогу виникнення) стадіях навантаження фактично встигає спрацювати лише частина 3 потенційно активних джерел АЕ (активація яких можлива при відповідному впливі). В наступних кроках (збільшеного $\Phi_{i}$ ) при “неправильно" вибраних кроках та часах зміни $\Phi_{i}$ беруть участь також джерела, для спрацьовування яких потрібен менший рівень $\Phi_{i}$, штучно збільшуючи активність АЕ та кількість взаємодіючих джерел. 


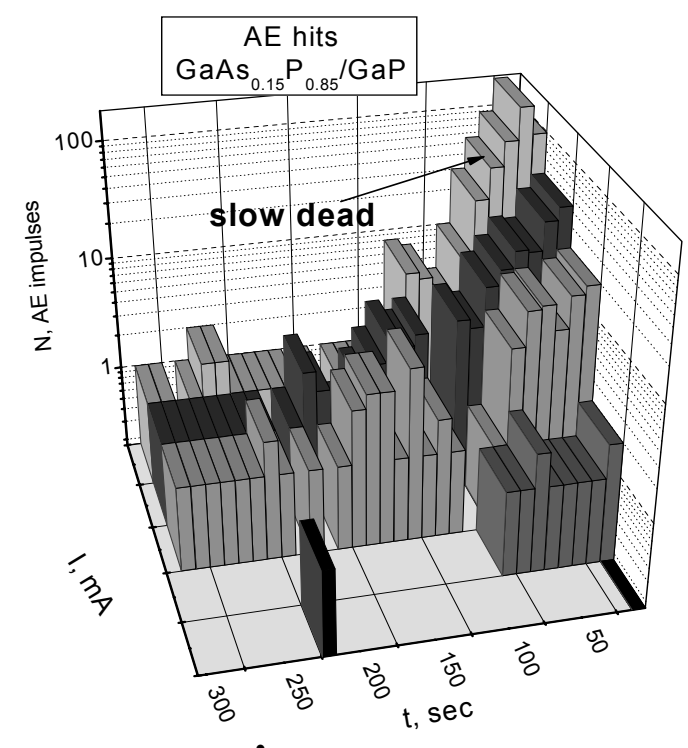

Рис. 3. Залежності $\dot{N}(t)$ для динаміки АЕ з “занадто великим” кроком

Таким чином, динаміка процесу $\mathrm{AE}$ в гетеpоструктурах $G a N / G a I n N$ та $G a P A s / G a P$ добре узгоджується з основними висловленими припущеннями - AE є детермінованим в часі хаотичним релаксаційним процесом, параметри $\mathrm{AE}$ залежать від величини зміни та швидкості зміни рівня зовнішнього фіксованого навантаження, кількості однотипних джерел АЕ, активованих цим впливом на протязі часу його дії, а також дисперсією деяких параметрів цих джерел АЕ.

\section{Список літератури}

1. Шустер $Г$. Детерминированный хаос: Введение. - М.: Мир. 1988. - С. 240.

2. Ляшенко О.В. Акустична емісія матеріалів зі складною структурою дефектів як детермінований хаотичний релаксаційний процес./ Структурна релаксація в твердих тілах // Зб. наук. праць, ред. Мозговий О.В. - 2006. - Вінниця: ТОВ "Планер", С. 29-31.

3. Грешников В.А., Дробот Ю.Б. Акустическая эмиссия. - М.:Изд. Стандарт., 1976.

4. Гусев O.B. Акустическая эмиссия при деформировании монокристаллов тугоплавких металлов / Гусев О.В. - М.: Наука, 1982. - 107 с.

5. Lord A.E. Acoustic Emission /in Physical Acoustics, vol.XI, Ed. by W.Mason. - N.Y., 1975, P. 289-353.

6. Велещук В.П., Ляшенко О.В. Акустична емісія світловипромінювальних структур на основі сполук $\mathrm{A}^{3} \mathrm{~B}^{5}$ обумовлена постійним прямим струмом // Український фізичний журнал. - 2003. - Т. 48, № 9. - С. 941-945.

7. Велешук В.П., Ляшенко О.В., Мягченко Ю.О., Чуприна Р.Г. Эволюция спектров электролюминесценции и акустическая эмиссия эпитаксиальных структур GaAsP // Журнал прикладной спектроскопии. - 2004. - Т. 71, № 4. - С. 508-511.

8. Велешук В.П., Власенко О.І., Ляшенко О.В. та інш. Акустична емісія світловипромінювальних структур на основі сполук $\mathrm{A}^{3} \mathrm{~B}^{5}$ обумовлена постійним прямим струмом //Український фізичний журнал. - 2008. - Т.53, № 3. - С.239-245.

9. Ikoma T., Ogura M., Adachi Y. Acoustic-emission study of defects in GaP light-emitting diodes // Appl. Phys. Lett. - 1978. - Vol.33 №5 P. 414-415.

10. Чишко K.A. Дислокационный механизм излучения звука при развитии трещины в кристалле // ФTT. - 1992. - Т. 34, № 3. - С. 864-869.

11. Нацик В.Д., К.А. Чишко Звуковое излучение дислокаций, движущихся у поверхности кристалла // ФТТ. - 1978. - Т. 20, № 2. - С. 457-465.

12. Ляшенко О.В. Моделювання динаміки акустичної емісії матеріалів //Вісник Київського університету, серія фіз. - мат. науки. - 2004. - № 3. - С. 20-23.

13. Василенко Н. Д., Горбатюк А. Я. Образование микровключений матричного металла 3 группы в моно-

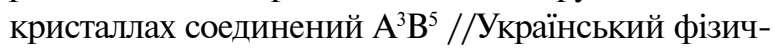
ний журнал. - 1989. - Т. 34, № 4. - С. 618-623.

14. Василенко Н.Д., Краснов В.А., Крыжановский А.Н., Чернер В.M. Процессы дефектообразования и их влияние на механические напряжения в структурах фосфида галлия зеленого свечения // Изв. вузов.Физика. - 1991. - Т. 34, № 1. - С. 23-27.

15. Василенко Н.Д. Внутренние механические напряжения в эпитаксиальных структурах фосфида галлия // Изв.Вузов. Физика.- 1983.- Т. 26, №1.- C. 122-124.

16. Берг А.А. Светодиоды / А.А. Берг, П.Д. Дин. - М.: Мир, 1979. - 686 с.

17. Птащенко А.А. Деградация светоизлучающих диодов. Обзор // Журнал прикладной спектроскопии. $-1980 .-$ Т. 33, № 5. - C. 781-803.

18. Guo X., Schubert E.F. Current crowding in GaN/In$\mathrm{GaN}$ light emitting diodes on insulating substrates // J. Appl. Phys. - 2001. - Vol. 90, №8 - P. 4191 - 4195.

19. Shatalov M., Simin G., Adivarahan V., Chitnis $A$. Lateral current crowding in deep UV light emitting diodes over sapphire substrates // Jpn. J.Appl.Phys. 2002. - Vol. 41, № 8. - P. 5083-5087.

20. Ляшенко О.В., Перга В.М., Тхорик В.А. Связь электрических шумов с акустической эмиссией в элементах оптоэлектроники // Тез. Докл. координ. совещ. соц. стран по физ. пробл. оптоэлектроники. - Баку. - 1989. - С.89.

21. Vlasenko O.I., Veleshchuk V.P., Lyashenko O.V. Acoustic emission, electrical and light fluctuations in optoelectronic devices// AIP Proceedings. 2005. - Vol. 780, P. 389-392.

22. Lyashenko O.V., Veleshchuk V.P., Vlasenko O.I., Chuprina R.G. Dynamics and time correlation of acoustic emission, electrical noises and quantum yield fluctuations in optoelectronic devices // AIP Proceedings. -2007 . - Vol. 922. - P. 216-222. 